\title{
Umgang mit einem Kindsverlust
}

\section{Julia Rippstein}

Redaktorin Schweizerische Ärztezeitung

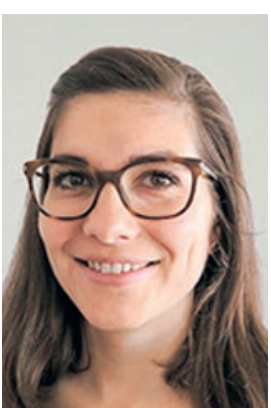

Noch nie hatte ich privat so viel mit Ärztinnen, Pflegefachpersonal und anderen Berufsgruppen des Gesundheitswesens zu tun wie im Jahr 2021. Eigentlich war mir bis dahin gar nicht richtig klar, was es bedeutet, eine Patientin zu sein. Im vergangenen August erfuhr ich es jedoch, als mir in der 16. Schwangerschaftswoche die Hiobsbotschaft überbracht wurde, dass das Kind in mir nicht mehr lebte. Wenn ich nun, fünf Monate später, sagen kann, mich von diesem traurigen und einschneidenden Ereignis einigermassen erholt zu haben, so habe ich es namentlich all den medizinischen Fachfrauen zu verdanken, die sich in diesen schwierigen Wochen um mich gekümmert und mich begleitet haben. Dabei verwende ich bewusst die weibliche Form, da ich nur einmal von einem Mann betreut wurde. Beispielhaft für die Interprofessionalität, die mir zuteilwurde, steht eine Botschaft aus dem Begleitmaterial, das ich erhalten habe: «Wir als Ärztinnen und Ärzte der Frauenklinik sind für Sie da. Wir begleiten und unterstützen Sie beim Abschiednehmen von Ihrem Kind, gemeinsam mit Hebammen und Pflegefachfrauen.» In der Gynäkologie und Geburtshilfe kommt der interprofessionellen Zusammenarbeit eine besondere Bedeutung zu. Das ist mir durch dieses Unglück bewusst geworden, umso mehr, als ich mich derzeit im Rahmen unserer Artikelreihe mit dem Thema Interprofessionalität beschäftige.

Während meines 24-stündigen Spitalaufenthalts für die stille Geburt, die das Ausstossen des toten Fötus aus dem Mutterleib beschreibt, erlebte ich das perfekte Zusammenspiel der Hebammen: Sie kümmerten sich intensiv um mich und sorgten dafür, dass diese Erfahrung für mich und meinen Partner, der die ganze Zeit an meiner Seite war, physisch und psychisch so schmerzfrei wie möglich verlief.

Wir konnten auch mit einer Seelsorgerin sprechen, die fragte, wie wir uns von unserem Kind verabschieden wollten. Eine solche Begleitung hatte ich nicht erwartet, aber es war beruhigend und wohltuend, ein so sensibles Thema wie den Tod mit einer Expertin besprechen zu können. Viele Fragen kommen in einer solchen Situation auf: Was geschieht mit dem totgeborenen Kind? Welche Möglichkeiten einer Abschiedszeremonie gibt es? Diese Fragen wurden bei der Betreuung von Frauen, die eine Fehlgeburt erlitten haben, lange Zeit vernachlässigt. Doch eine spirituelle Begleitung, selbst wenn es sich nur um ein kurzes Gespräch handelt, ist sehr sinnvoll. Denn das Abschiednehmen durch ein Ritual - das auch einfach darin bestehen kann, sich einige Augenblicke in der Nähe des Babys aufzuhalten hilft, den Tod annehmen und trauern zu können.

Diese Erfahrung im Spital hat mir gezeigt, wie eingespielt die Abläufe sind und wie gut definiert die Rollen: Jede weiss genau, was sie zu tun hat und welche Informationen sie wann an wen weitergeben muss. Einzig ein technischer Eingriff bei der Entfernung der Plazenta wurde von einer Ärztin durchgeführt. Mit Hilfe einer Ultraschalluntersuchung stellte sie sicher, dass in der Gebärmutter nichts zurückgeblieben war. Sie führte auch einige Wochen später die Nachuntersuchung durch. Während all dieser Zeit hatte ich nie den

Leider zeigt die gute interprofessionelle Zusammenarbeit auch, dass ich kein Einzelfall bin.

Eindruck, dass irgendwo Informationen auf der Strecke geblieben wären. Dies zeigt, dass die Interprofessionalität in diesem Bereich funktioniert, aber leider auch, dass ich kein Einzelfall bin.

Wir hätten zusätzliche psychologische Unterstützung erhalten können, wenn wir dies gewünscht hätten. Glücklicherweise mussten wir dieses Angebot nicht in Anspruch nehmen.

Die interprofessionelle Betreuung hat viel dazu beigetragen, dass es mir nun wieder besser geht. Was mir aber wohl am meisten geholfen hat, meine Fehlgeburt zu akzeptieren, war, dass ich mit meinem Partner, meiner Familie und meinem engen Freundeskreis darüber gesprochen habe. Das Thema anzusprechen war zwar schmerzhaft, aber notwendig, um das Geschehene zu verarbeiten und so darüber hinwegzukommen.

Ich möchte alle Frauen und Paare, die dasselbe durchgemacht haben, ermutigen, das Erlebte in Worte zu fassen und nach aussen zu tragen. Um ein totgeborenes Kind trauern zu müssen, ist alles andere als selten, wird aber leider oft tabuisiert. Laut Bundesamt für Statistik lag die perinatale Sterblichkeit in der Schweiz im Jahr 2019 bei 6,3 Fällen pro 1000 Geburten [1]. Spontane Fehlgeburten bis zur 20. Woche machen 15 bis $20 \%$ der bestätigten Schwangerschaften aus [2] und sind damit das am weitesten verbreitete Problem bei Schwangeren. Nur wenn man das Tabu bricht, kann man den Betroffenen helfen, das Erlebte zu verarbeiten. 